\title{
Kronik bel ağrılarında girişimsel yöntemler
}

\section{Interventional procedures for chronic low back pain}

\author{
Emin Alp Yentür \\ Celal Bayar Üniversitesi Tıp Fakültesi, Anesteziyoloji ve Reanimasyon Anabilim Dalı, Algoloji Bilim Dalı, Manisa
}

Bu makalede konservatif tedavi yaklaşımları ile yeterli rahatlama sağlanamayan bel ağrılı hastalarda uygulanan girişimsel ağrı tedavi yöntemleri anlatılmıştır.

Anahtar sözcükler: bel ağrısı; girişimsel tedaviler; ağrı tedavisi
In this article, interventional procedures are described for patients who could not find sufficient benefit from conservative low back pain therapies.

Key words: low back pain; interventional procedures; pain management

\section{B}

el ağrısı tedavisinde girişimsel yöntemlerin kullanımı, son yıllarda giderek artış göstermektedir. Bunun temel nedeni; medikal tedavi, fizik tedavi gibi konservatif tedavi biçimleri ile yeterli rahatlama sağlanamayan hastaların, cerrahi öncesinde göreceli konservatif yöntemleri deneme isteğidir.

Diğer taraftan, bu tedavi modalitesine kanıta dayaIı tıp çerçevesinde baktığımız zaman, bir miktar hayal kırıklığı yaşandığını da itiraf etmek gerekir. Çünkü, girişimsel ağıı tedavisi çalışmalarının çoğu, kanıta dayalı tıp açısından güçsüz çalışmalardır. Bunun temelinde, etik nedenler ve hastaların plasebo kontrollü randomize bir çalışmaya ikna edilmesindeki zorluk yatmaktadır.

\section{GIRIŞiMSEL UYGULAMALAR}

\section{Tetik Nokta Enjeksiyonları}

Miyofasyal ağrı sendromu, kas gövdesinde tetik noktaların varlığı ile karakterize, ağrılı bir kas problemidir. Tetik noktalar, palpe edilebilen kaslarda, ele gelen gergin bantların içinde bulunan fokal hassas nodüllerdir ve üzerine bastırmak ile yansıyan ağrılara neden olur. Travel ve Simons, bel bölgesindeki ağrıların önemli kısmının musküler faktörlere bağlı olduğunu, bunların da genellikle iliopsoas ve kuadratus lumborum kaynaklı olduğunu bildirmişlerdir. ${ }^{[1]}$

Tetik nokta tedavisinde genel yaklaşım olarak, soğuk sprey ve germe, ultrasonografi, manipülatif tedaviler gibi farklı tedavi modaliteleri uygulanırken, kronikleşen olgularda tetik nokta enjeksiyonu bunların en bilinenidir. Tetik nokta enjeksiyonları, miyofasyal ağrı sendromu nedeni ile, kas gövdesinde bulunan aktif tetik noktaların inaktive edilmesi amacıyla uygulanan bir tedavi biçimidir. ${ }^{[2]}$

Tetik noktaların inaktivasyonu ile ilişkili birçok olası mekanizma öne sürülmüştür. Bunlar arasında en çok kabul gören, lokal anestezik enjeksiyonu ile, kasılmaya yol açan tetik noktayla santral sinir sistemi arasındaki duyusal-motor döngünün kırılmasıdır. Bunun dışında, iğnenin mekanik etkisi veya lokal anesteziklere bağlı fokal kas nekrozu ile tetik noktaların haraplanması, kontr-irritasyon, bölgesel hücre haraplanması sonucunda intrasellüler potasyumun hücre dışına çıkması da öne sürülmektedir. ${ }^{[3]}$

Teknik: Ağrılı kas üzerinde gergin bantların (taut band) palpe edilmesi ve lokal ağrılı yanıtın alınmasından sonra, bu bölgeye ince bir enjektör iğnesi ile girilerek, iğne uyarısına bağlı kas üzerinde seğirme alınan noktaya lokal anestezik (tek başına veya steroid ile birlikte) enjeksiyonu yapılır.

\section{Sakroiliak veya Feset Eklem Steroid/Lokal Anestezik Enjeksiyonları}

Osteoartroz, sinoviyal eklemlerde kartilaj dejenerasyonu ile ortaya çıkan bir tablodur. Primer etken inflamasyon olmamasına karşılık, genellikle sekonder

- Illetişim adresi: Prof. Dr. Emin Alp Yentür, Manisa Celal Bayar Üniversitesi Tıp Fakültesi Hastanesi, Anesteziyoloji ve Reanimasyon Anabilim Dalı, Uncubozköy, Manisa Tel: 0533 - 3632418 e-posta: ayentur@yahoo.com

- Geliștarihi: 20 Șubat $2017 \quad$ Kabul tarihi: 20 Șubat 2017 
olarak gelişen sinovit tabloya hakimdir. İleri yaş, genetik yatkınlık ve fazla kilo, etiyolojide sıklıkla öne çıkan faktörlerdir. ${ }^{[4]}$

Bu olgularda birçok tedavi modalitesi uygulansa da, eklem için steroid ve lokal anestezik enjeksiyonları belki de en sık kullanılan tedavi seçeneğidir.

\section{Sakroiliak Eklem (SIE) Enjeksiyonu}

SiE posterioru S1 ve S2, ventrali ise L3-S2 segmental sinirlerinden innerve olur. ${ }^{[5]}$ SiE enjeksiyonu, bir taraftan ağrının eklem mi eklem dışı kaynaklı mı olduğu konusunda tanı koymak için kullanılırken, diğer taraftan da tedavi amaçlı kullanılan bir yöntemdir.

Sakroiliak eklemin inflamatuvar ağrılarında, floroskopi eşliğinde eklem içi steroid enjeksiyonu sık kullanılan bir tedavi seçeneğidir. Uzun etkili depo-steroidlerin analjezik etkinliği haftalar hatta aylar sürebilir. Bunun etkisiz kaldığı veya rekürrens gelişen olgularda ise, radyofrekans (RF) ablasyon diğer bir seçenek olarak akla gelebilir. ${ }^{[6]}$

\section{Teknikler:}

Steroid enjeksiyonu: Sakroiliak eklem bloğu için, hasta pron pozisyonda yatarken eklem önce a.p. görüntülenir. Daha sonra, eklem aralığının en net görüldüğü açıya kadar C-kolu oblik pozisyona getirilir. Eklem aralığının ön-arka mesafesinin geniş olması nedeni ile, görüntüleme sırasında floroskopi cihazının C-kolu yaklaşık $20^{\circ}$ 'ye kadar mediyale doğru yatırılması gerekebilir. Bu açıda, eklemin ön ve arka kenar çizgileri üst üste gelir. Daha sonra, eklemin alt kenarına yakın bir noktadan spinal iğne ile tünel görüntüleme tekniği kullanılarak eklem aralığına girilir. İlaç enjeksiyonu öncesinde, iğnenin yerinin opak madde ile doğrulanması gerekir.

RF uygulama: Tam bir tedavi için, kök gangliyonları ve faset eklemlere RF uygulamak gerekir. S1-2-3 dorsal kök gangliyonlarına pulsed RF ve L4-5 ve L5-S1 mediyal dallarına konvansiyonel RF uygulaması önerilir. ${ }^{[5]}$

\section{Faset Eklem Bloğu}

Kapsül, sinoviyal membranlar ve subkondral kemiğin zengin innervasyonu nedeni ile, faset eklemler akut ve kronik bel ağrılarının önemli bir kaynağını oluşturur. Faset ağrısı, esas olarak osteokondral olabilir. Ancak, sıklıkla tabloyu başlatan olgu, eklemde travmaya bağlı kapsülün gerilmesine, yırtılmasına veya kapsül sıvısının neden olduğu distansiyona bağlı sinoviyal reaksiyondur. Bütün bu mekanizmalar, eklem kapsülünde yoğun olarak bulunan nosiseptörlerin mekanik veya kimyasal uyarısına neden olur. ${ }^{[7]}$
Tanı için, eklem içi veya mediyal dala lokal anestezik uygulayarak gerçekleştirilen diyagnostik bloktan yararlanılır. Diyagnostik blok sonucunda ağrısı rahatlayan hastalara mediyal dal RF termokoagülasyon uygulanabilir. Her mediyal dal, bir üst ve bir alttaki olmak üzere iki faset eklemi innerve ederken, her faset eklem de bir üst ve bir alttaki mediyal daldan innerve olur. ${ }^{[8,9]}$

Burada üç ayrı blok uygulanabilir. Bunlar; mediyal dal bloğu (lokal anestezik ile), intra-artiküler enjeksiyon ve mediyal dal RF termokoagülasyonudur.

\section{Mediyal dal bloğu}

Bu işlem diyagnostik amaçla uygulanır. "Ağrı faset eklemden mi kaynaklanıyor; eğer öyleyse hangi eklemden kaynaklanıyor?" sorularına yanıt aramak için kullanılan bir bloktur.

Teknik: Hasta floroskopi masasında pron pozisyonda yatar. Girişim seviyesi a.p. görüntüleme ile saptandıktan sonra, C-kolu işlem yapılacak tarafa doğru yaklaşık $20^{\circ}$, "Scottie dog" görüntüsü elde edilinceye kadar yatırılır. Daha sonra, tünel görüntüleme tekniği ile, "köpeğin gözünün posterior kenarı" yani superior artikülat proses ile transvers prosesin kesişim yeri hedeflenir. İğne, kemik teması alınıncaya kadar ilerletilir. Ön-arka ve lateral görüntüler ile iğnenin yeri doğrulandıktan sonra, $0,5 \mathrm{ml}$ lokal anestezik enjekte edilerek blok gerçekleştirilir.

\section{İntra-artiküler enjeksiyon}

Bu girişim daha çok terapötik amaçla kullanılsa da, intra-artiküler steroid enjeksiyonunun faset eklem artrozu tedavisindeki yeri tartışmalıdır. Daha çok lokal anestezikler ile, tanı amaçlı yapılan bir işlemdir. Hastanın ağrısının rahatlaması halinde, bu hastalara mediyal dal RF termokoagülasyon uygulanır.

Teknik: İntra-artiküler faset eklem enjeksiyonu, pron pozisyonda, lomber lordozu düzeltmek amacı ile karının altına yastık konularak uygulanır. Girişim yapılacak seviyeye göre değişse de, eklem aralığını görebilmek için genellikle oblik floroskopik görüntüleme tercih edilir. Burada, eklemin kavisli ve C-kolunun oblik hareketi sırasında ilk görülen çizginin eklemin posterior kısmı olduğunu bilmek önemlidir. İşlem, spinal iğne ile tünel tekniği uygulanarak gerçekleştirilir. Burada dikkat edilmesi gereken temel noktalardan birisi, eklem aralığının çok küçük olması nedeni ile, kapsül hasarını arttırmamak için, enjekte edilecek steroid ve/veya lokal anestezik ilaç volümünün çok az olmasıdır $(\leq 0,5 \mathrm{ml}) .{ }^{[6]}$

\section{Mediyal dal RF}

Faset eklem ağrısı tedavisi için geçerliliği kabul görmüş tek tedavi, mediyal dal RF uygulamasıdır. ${ }^{[10-12]}$ 
Posterior ramusun mediyal dalı, en güvenilir biçimde, superior artikülat prosesin alt kenarı ile transvers prosesin birleşme yerindeki olukta bloke edilir. Her eklem, daha önce de belirtildiği gibi iki segmentten innerve olur. Her segmental sinir ise, iki ayrı faset ekleme ilave olarak eklemin üstündeki yumuşak dokuları da innerve eder. Bu nedenle, etkin bir tedavi için, işlem en az iki seviyeye uygulanmalıdır. ${ }^{[6]}$

Teknik: Mediyal dal denervasyonu, transvers proses ile pedikülün birleştiği yerde gerçekleştirilir. İşlem, mediyal dal bloğunda anlatıldığı şekilde uygulanır. İğne ucunun yerinin lateral görüntü ile doğrulanması sırasında hedef, transvers prosesin hemen üstü, superior artikülat prosesin lateral kenarı olmalıdır. Bu noktaya $50 \mathrm{~Hz}$ ile yapılan duyusal uyarıya yanıt alınıp, $2 \mathrm{~Hz}$ uyarı ile 2 Volt'a kadar motor yanıt alınmaması halinde $80^{\circ} \mathrm{C}, 90$ sn lezyon uygulanır.

\section{Transforaminal Epidural Steroid Enjeksiyonu}

Lomber radiküler ağrı, spinal sinirlerin ve dorsal kök gangliyonunun inflamasyonu veya irritasyonu sonucunda ortaya çıkar. Bunun en sık karşılaşılan nedeni, disk hernisi veya foraminal stenozdur. Epidural alana steroid uygulanmasının ardında yatan mantık, kortikosteroidin intervertebral foramene enjeksiyonu ile, steroidin sistemik uygulamaya göre daha yoğun olarak inflame nöral yapıların çevresine uygulanmasıdır. Steroidin interlaminer enjeksiyonu sonucunda, ilaç genellikle ventral veya lateral bölgede bulunan hedeflenen dokuya, yani segmenter sinire ve dorsal kök gangliyonuna ulaşamayabilir. Halbuki, transforaminal yaklaşım ile tam istenen bölgeye enjekte edilmektedir.

Teknik: Floroskopi eşliğinde pron pozisyonda uygulanır. Önce, hedeflenen foramene uyan pedikül a.p. görüntüleme ile saptanır ve pedikülün hemen altında bulunan end-plate tek çizgi haline getirilir. Daha sonra C-kolu, pedikülün altındaki superior artikülat prosesin ucu, pedikülün tam alt hizasına (saat 6 hizasına) gelinceye kadar oblik pozisyona getirilir. İğne giriş noktası, superior artikülat prosesin üst ucu ile pedikülün arasındaki bölgedir. Giriş için "güvenli üçgen”, a.p. görüntülemede pedikülün alt kenarı, spinal sinir ve vertebra gövdesinin lateral kenarı arasında kalan bölgedir. Burası arter yaralanması açısından en güvenli enjeksiyon bölgesidir. İğne, tünel görüntüleme tekniği ile iğne ilerletilir ve ucunun pozisyonu a.p. ve laretal görüntüler ile doğrulanır. İğne ucunun son noktası, a.p. görüntüde pedikülün hemen kaudalinde, saat 6 pozisyonudur. Lateral görüntüde ise, iğne ucu foramenin orta veya ventral bölümünde ve subpediküler bölgede olmalıdır. Bu konumda iğne, segmenter sinirin dorsal kök gangliyonu (DKG)'nun lateral ve rostralindedir. Burada enjekte edilen opak madde foramende iğne ucundan mediyale doğru, pedikülün rostraline yayılmalıdır. Fazla oblik yaklaşımda ve iğne saat 6 pozisyonunun daha ilerisine ilerletilirse, intratekal enjeksiyon meydana gelebilir.

\section{DKG Pulsed RF}

DKG, girişimsel ağrı tedavisinde en önemli hedeflerden birisidir. Gangliyonda bulunan primer afferent duysal nöronlar, periferik nosiseptörler ile santral sinir sistemi arasıdaki esas bağlantıyı oluşturur. Burada lateralize herniye olmuş bir disk veya spondilolistezis nedeni ile mekanik travma, nükleus pulpozusun dışarı çıkması nedeniyle kimyasal irritasyon ve herpes zoster gibi enfeksiyöz ajanlar nedeni ile, problem karşımıza çıkar.

DKG'ye steroid enjeksiyon dışında, pulsed RF (PRF) de tedavi amacı ile uygulanmaktadır. Pulsed ve düşük ısılı RF uygulaması, nöral yapılarda hasara neden olmaz. ${ }^{[13]}$ PRF'nin terapötik etkisinin, termal etkiden daha çok elektrik alana bağlı olduğu düşünülmektedir. ${ }^{[14]}$ DKG'ye uygulanan düşük ısılı elektrik alanının ağrıda uzun süreli rahatlama sağlaması, implante edilebilen ve DKG çevresinde sürekli elektrik alanı oluşmasını sağlayan DKG stimülasyon sistemlerinin geliştirilmesine de yol açmıştır. ${ }^{[15]}$ Ancak, PRF'nin hangi mekanizma ile klinik yarar sağladığı konusunda kesin bir bilgi yoktur.

Teixera, DKG-PRF'yi cerrahiye aday radiküler ağrılarda önermiş, PRF ile tedavi olan 13 hastanın 12'sinde en az bir yıl süre ile cerrahiye ihtiyaç olmadığı ve bunun epidural steroid enjeksiyonuna alternatif tedavi olduğunu öne sürmüştür. ${ }^{[16]}$

Teknik: DKG'ye ulaşmak için en iyi yöntem, retronöral yaklaşımdır. Bu yaklaşımda hedef nokta, lateral görüntülemede yukarıdan aşağı doğru forameni tam ortadan kesen bir çizgi ile foramenin 1/3 üst kısmından geçen transvers çizginin kesişme noktasıdır. Bunun için, transforaminal girişimde olduğu gibi, a.p. görüntülemede ilgili vertebranın end-plateleri tek bir çizgi haline getirildikten sonra, SAP vertebra gövdesinin 1/3'üne gelinceye kadar oblik görüntü alınır. Bu, yaklaşık olarak $20-25^{\circ}$ oblik görüntüleme ile sağlanır. İğnenin giriş noktası, transforaminal girişim noktasının hafifçe alt ve lateralidir. Pedikülün hemen altı ve foramenin 1/3 üstü, giriş noktasıdır. İğne tünel görüntüleme tekniği ile ilerletilirken, a.p. görüntüde derinlik kontrolü yapılır. Burada, iğnenin şaftından ziyade ucunun DKG'ye dik gelmesi amaçlanır. Çünkü, KRF'nin tersine, PRF'de elektrik alan iğnenin ucundadır.

Amaçlanan noktaya ulaşıldığında, duyusal uyarı yapılır. Hastanın, ağrı olan dermatomda uyarıyı hissetmesi gerekir. PRF uygulamasında motor lifler hasara 
uğramayacağı için, işlem öncesinde motor uyarı yapmaya gerek yoktur. İşlem, 45 Volt ile 3-4 dakika kadar uygulanır. Bu sırada ısının $42^{\circ} \mathrm{C}$ 'yi geçmemesine dikkat edilir.

\section{Intradiskal Girişimler}

\section{Provokatif diskografi}

Ağrının gerçek kaynağını gösteren, bu şekilde en etkin tedaviye yönlendiren, aynı zamanda da hastaların gereksiz yere ameliyat edilmesini engelleyen doğrulama testidir. Bu test, internal disk hasarını göstermenin yanında, hastanın ağrısını provoke ederek ağrılı diskin seviyesinin belirlenmesine de yardım eder. Provokatif diskografi, diskojenik ağrı tanısında altın standarttır. ${ }^{[17]}$

Provokatif diskografi, post-diskektomi diskleri veya rekürren disk herniyasyonlarında olduğu gibi manyetik rezonans (MR) görüntüleme ve miyelografinin çok başarılı olmadığı zor olgularda işe yaramaktadır. ${ }^{[18]}$ Buna karşılık, intervertebral diskin ağrının kaynağı olup olmadığının saptanması için bu işlemin yapılmasının gerekliliği, ayrıca diskografi ile diskin ağrıya neden olduğunun gösterilip gösterilemeyeceği de tartışmalı konulardır. ${ }^{[19]}$

Teknik: Hasta pron posizyonda yatarken, floroskopik oblik görüntüleme ve ekstrapediküler yaklaşım ile diske girilir. Giriş yeri, hastanın ağrısının karşı tarafindan olmalıdır. Bu yolla, hastanın kontrast madde enjeksiyonuyla provoke edilen ağrısı ile annulusa giriş ağrısının ayırt edilebilmesi sağlanır. ${ }^{[17]}$

Girilmesi planlanan disk a.p. görüntülendikten sonra, skopinin C-kolu, SAP üst ucu vertebra gövdesinin ortasına gelecek şekilde oblik pozisyona getirilir. Giriş noktası, superior artikülat prosesin hemen lateralidir. İğne, tünel tekniği ile ilerletilir. Bu şekilde, iğne segmental sinirin altından geçer ve diskin orta noktasında, annulus fibrozusa penetre eder. Diskin santraline kadar girilir. İğne ucunun yeri a.p. ve lateral görüntülemelerle teyit edilir. ${ }^{[17]} \mathrm{Bu}$ noktada, disk içine yavaşça opak madde enjekte edilir. Bu enjeksiyon işlemi; 3,5 ml volüme ulaşılmışsa hasta belirgin ağrı hissederse, epidural veya vasküler opak yayılım görülürse, ya da maksimum 90 psi basınca erişilmişse sonlandırılır. ${ }^{[19,20]}$

\section{IDET (İntradiskal Elektrotermal Tedavi)}

Son 20 yıl boyunca, disklerden kaynaklanan ağrıların tedavisinde; IDET, anüloplasti, RF lezyonu, kortikosteroid, ozon, hipertonik dekstroz ve metilen mavisi enjeksiyonu, perkütan disk dekompresyonu gibi farklı birçok intradiskal girişim tanımlanmıştır. Ancak, intervertebral disklerden kaynaklanan kronik non-spesifik bel ağrılarının tedavi etkinlikleri konusunda, intradiskal tedavi yaklaşımları hakkında yeterli kanıt bulunmamaktadır. Bu ağrılarda, ramus rekürrens RF tedavisi önerilmektedir.

IDET, iyi seçilmiş bel ağrılı hastalarda pozitif terapötik etkiye sahip bir yöntemdir. Hasta seçiminin titizlikle yapılması, başarı şansını yükseltir. İntervertebral disk, özellikle de annulus dejenerasyon, yaralanma veya inflamasyon sırasında artan nosiseptif sinir reseptörleri içerir. Reseptörlerdeki bu artış, bel ağrısının şiddetlenmesine ve sürekli hal almasına neden olur. ${ }^{[21-23]}$ Dejenere diskte, sıklıkla annüler fissürler boyunca ortaya çıkan ileri derecede vaskülarizasyon, inflamatuvar sitokinlerin bu bölgelere taşınmasına neden olur. Normalde annulusun dış 1/3'ünde sınırlı olan nosiseptörler de, bu yeni oluşan fissürlerin çevresindeki neovaskülarizasyon bölgelerinden dejenere diske penetre olur. ${ }^{[24]}$

IDET uygulaması, kollajen dokunun kalınlaşıp kontrakte olmasına, bu yolla revaskülarizasyonun engellenmesine neden olur. IDET'in neden olduğu termokoagülasyon, annüler duvar içindeki nosiseptörleri de tahrip eder. Ayrıca, kollajen yapıda ortaya çıkan değişiklik, annüler fissürlerin küçülmesine ve diskin stabilitesinin artmasına da neden olur. ${ }^{[25]}$

Teknik: IDET, perkütan olarak posterior annulus ile nükleus arasına yerleştirilen termal kateter yardımı ile yapılan bir işlemdir; $17 \mathrm{G}$ iğne ile floroskopi eşliğinde hedeflenen diske girilir; termal kateter bu kanülün içinden amaçlanan pozisyonda yerleştirilir. Burada dikkat edilmesi gereken nokta, kateterin bütün posterior annulus ile nükleus arasındaki bölgeyi kapsayacak şekilde yerleştirilmesidir. Daha sonra, bu bölgenin $4 \mathrm{dk}$ süresince $90^{\circ} \mathrm{C}$ ssıtılması gerekir.

\section{Rami Komünikantes Bloğu}

İntervertebral disk innervasyonunda, posterior annulus fibrozusun nosiseptif uyarıları, rekürren meningeal sinir tarafından sempatik zincirin ramus komünikantesine, oradan da dorsal kök gangliyonu ve medulla spinalise iletilir. Tek seviye diskojenik ağrısı olan hastalarda, komşu iki seviyede, bu sinirlere RF ablasyon uygulanmasının ağrıyı kestiğini bildiren randomize çalışma 28 yıl önce yayımlanmıştır. ${ }^{[26]}$

Teknik: Giriş yeri, a.p. görüntülemede vertebra sınırının $2,5 \mathrm{~cm}$ laterali ve transvers çıkıntının hemen altıdır. İğne dikkatlice, pedikülün altından, intervertebral foramenin superiorunda (sefaladında), hemen anterioruna ulaşacak şekilde yaklaşık $20^{\circ}$ oblik tünel görüntüleme tekniği ile ilerletilir. Lateral görüntüde iğnenin son noktası foramenin $0,5 \mathrm{~cm}$ anterioru, a.p. görüntüde ise vertebra gövdesinin lateralinde olmalıdır. Blok için $1 \mathrm{ml}$ \%2'lik lidokain ve $20 \mathrm{mg}$ triamsinolon enjekte 
edilir. Her ağrılı disk için işlem, ilgili diskin bir alt bir de üstünden gerçekleştirilir.

RF uygulamada da aynı teknik kullanılır. Duysal uyarı sonucunda, hasta uyarıy belinde hisseder. Daha sonra motor uyarı yapılır; bu defa yanıt alınmaması gerekir.

\section{Nöroplasti}

Epidural lizis, sıklıkla epidural skar dokusunun neden olduğu radikülopati ve sinir kökü entrapmanı olan hastalarda uygulanır. Burada, adhezyon bölgelerine lizis uygulamanın amacı, skar dokusunu geçip ilacı hedef bölgelere ulaştırabilmektir. Epidural fibrozisin kendisi ağrısızdır. Ağrının nedeni, sinirin ödem nedeni ile sıkışması ve irritasyonudur. Nöral foramenlerde, sinir köklerine epidural venler eşlik eder. Epidural skar dokusu venlerde sıkışmaya, bu da epidural alanda ödem gelişmesine neden olur. ${ }^{[27]}$

Teknik: Hasta pron pozisyonda yatarken, sakral hiatustan epidural aralığa kanül ile girilir. Önce, lateral görüntüleme ile iğnenin kaudal epidural bölgede bulunduğundan emin olunur. Daha sonra, a.p. görüntüleme eşliğinde, iğne S3 seviyesinin hemen altına kadar ilerletilir. Yaklaşık $10 \mathrm{ml}$ radyo-opak enjeksiyonu ile, iğnenin epidural aralıkta olduğu çam ağacı görüntüsü ile doğrulanır. Anormal epidurogram ile, fibrosise bağlı dolma defekti olan bölgeler görülür, Racz kateter bu bölgelere doğru yerleştirilir ve $10 \mathrm{ml} \mathrm{SF}$ içinde $1500 \mathrm{U}$ hiyaluronidaz enjekte edilir. Daha sonra, 10 $\mathrm{ml}$ enjektör ile $9 \mathrm{ml} \% 0,5$ lidokain ve $40 \mathrm{mg} / \mathrm{ml}$ triamsinolon hazırlanır. Bunun $3 \mathrm{ml}$ 'si test doz olarak verilir. İntratekal enjeksiyon olup olmadığını kontrol için bir süre beklenir. Test doz bir bulguya neden olmadiysa, geri kalanı da enjekte edilir ve kateter tespit edilir. Yirmi dakika sonra, derlenme odasında motor blok olmadığından emin olununca, $10 \mathrm{ml} \% 10$ hipertonik salin 30 $\mathrm{dk}$ içinde infüzyon halinde verilir. İnfüzyon için, hasta ağrılı taraf aşağıda olacak şekilde yan yatırılır ve infüzyon tamamlandıktan sonra $30 \mathrm{dk}$ daha bu pozisyonda beklenir. Bunu amacı, ödemli ve ağrılı sinir köklerinin hiperosmolar etkiye daha fazla maruz kalmasıdır. Takip eden iki günde, önce $10 \mathrm{ml} \% 0,5$ lidokain, 25-30 dk sonra da 30 dk'da 10 ml hipertonik salin infüzyonu, toplam üç kez olacak şekilde tekrarlanır.

\section{Epiduroskopi}

Epiduroskopi, epidural aralıkta bulunan ve ağrıya neden olan yapıları görerek tanı konulması ve tedavi uygulanması için kullanılan bir yöntemdir. Bu hastalarda epiduroskop kullanmanın avantajları; radiküler ağrının tanısının doğrulanması, adhezyonların mekanik olarak tedavisi ve ilaçların hedef dokuya uygulanabilmesi, şeklinde sayılabilir. ${ }^{[28]}$
Epiduroskopinin başarısı, vertebral kanalın anatomisinin iyi bilinmesine bağlıdır. Endikasyonları; epidural aralıktaki patolojinin incelenmesi, doğrudan ilaç uygulamak, skar dokusuna lizis uygulamak ve minimal invaziv cerrahi uygulamalar olarak sıralanabilir. En sık, kronik radiküler ağrısı veya bel ağrısı olan hastalarda patolojiyi saptamak ve tedavi uygulamak için kullanılmaktadır.

Teknik: İşlem için, hasta pron pozisyonda ve lomber lordozu düzeltmek için karnın altına yastık konularak yatırılır. Epidural aralığa giriş sakral hiatustan, Seldinger tekniği ile olur: $18 \mathrm{G}$ Tuohy iğnesi ile sakral hiatustan a.p. ve lateral görüntüleme ile girilir; $10 \mathrm{ml}$ opak madde enjekte edilerek ile epidurogram yapilı;; daha sonra iğnenin içinden kılavuz tel geçirilerek L5-S1 seviyesine kadar ilerletilir; cilde bistüri ile bir kesi yapılır; epidural iğnesi çıkartılır ve kılavuz telin üstünden sakral kanala dilatatör yerleştirilir. Bunu takiben dilatatör çıkartılıp, dilatatör ile birlikte sheath kılavuz tel üstünden yerleştirilir. Sakrokoksigeal bağ geçilinceye kadar, dilatatör ve sheath'in birlikte ilerletilmesi önemlidir. Floroskopi ile sheath'in konumu doğrulandıktan sonra, dilatatör ve kılavuz tel çıkartılır, sheath yerinde bırakılır. Daha sonra, epiduroskop sheath içinden epidural aralığa yerleştirilir.

\section{Kifoplasti-Vertebroplasti}

Başlıca üç esas klinik endikasyonu vardır: hemanjiyom, metastaz veya osteoporoza bağlı ortaya çıkan vertebra korpusunun ağrılı çökme kırıkları. Vertebra korpus kırıkları, hem akut hem de kronik ağrıya neden olabilmektedir. Floroskopi eşliğinde uygulanan kifoplasti ve vertebroplasti, bu ağrıların tedavisinde etkili girişimlerdir. Bu işlemler sırasında, vertebra korpusuna yerleştirilen iğne aracılığı ile sement enjekte edilerek kırık stabilizasyonu sağlanır.

Vertebroplasti ve kifoplastinin nasıl analjezi sağladığı net olarak bilinmemektedir. Bu konuda çeşitli teoriler vardır. Kırık oluşan vertebra gövdeleri, gücünü ve sertliğini yitirir. Sement (polimetilmetakrilatPMMA) enjeksiyonu, vertebra gövdesinin sertliğini ve bu yolla kırığın mekanik stabilizasyonunu sağlar. Güç, vertebra gövdesinin taşıdığı yük ile ilişkilidir; sertlik ise hasara uğrayan vertebra gövdesinin mikrohareketlerini sınırlar. PMMA enjeksiyonu ile sertlik ve güç tekrar sağlanırken, ağrılı mikro-hareketler de azalır.

Ağrı tedavisinde rol oynadığı düşünülen diğer mekanizmamalar ise, PMAA'nın neden olduğu termal ve sitotoksik reaksiyonlardır. Polimerizasyonun neden olduğu ısının, posterior annulus, sinuvertebral sinir ve segmental dorsal kök gangliyonu gibi çevre 
dokularda nöromodülatör etki yarattığı öne sürülmektedir. ${ }^{[29]}$ In vivo çalışmalarla, polimerizasyon sırasında ortaya çıkan ısının $50^{\circ} \mathrm{C}$ 'nin üzerine çıktığı, bunun da interosseöz ve periostal sinirlerde hasara yol açtığı gösterilmiştir. [30]

Vertebroplasti hastanın ağrısını geçirebilir, fakat vertebradaki deformitede düzelme olmaz. Buna karşılık, balon kifoplasti sonrası ağrı iyileştiği gibi, deformite de düzeltilebilmektedir.

Heriki işleme de benzer şekilde başlanır. En sıkkullanılan yöntem, transpediküler yaklaşımdır. Vertebroplasti sırasında korpus içine doğrudan sement enjeksiyonu yapılırken, kifoplastide korpusa önce bir balon yerleştirilir ve bu şişirilir. Daha sonra, bunun oluşturduğu kaviteye sement enjekte edilir. Balonun amacı, sement enjeksiyonu için kavite oluşturmanın yanı sıra korpus yüksekliğini de eski haline getirmektir. İşlem sırasında, girişime bağı ortaya çıkabilecek nörolojik septomlarla ilgili hastanın sözel geri bildiriminin alınabilmesinin gerekliliği nedeni ile, genel anestezi tercih edilmez.

Teknik: Transpediküler ve parapediküler olmak üzere, iki farklı teknik kullanılmaktadır. Genellikle, lomber ve alt torasik vertebrada transpediküler, üst torasik vertebrada ise parapediküler teknik uygulanır.

Transpediküler yaklaşım için, önce a.p. görüntüleme ile girişim yapılacak seviye seçilir ve vertebranın end-plate'leri tek bir çizgi haline getirilir. Bazen bunu yapmak, vertebradaki deformite nedeni ile zor olabilir. Daha sonra, skopinin C-kolu pedikül vertebra korpusunun ortasına gelecek şekilde oblik pozisyona getirilir. $\mathrm{Bu}$, tünel görüntüleme tekniğidir. İğne, pedikülün tam ortasına hedeflenir. İğne pediküle dayandıktan sonra, pedikülün içinde (kemikte) vidalama tekniği veya çekiç kullanarak ilerletilir. Bu sırada sık sık, floroskopik görüntüleme ile iğnenin pozisyonu kontrol edilir; a.p. görüntü ile, pedikülün mediyal korteksinin hasarlanmamasına dikkat edilir. Lateral görüntüde ise, kanülün pedikül içinde olduğu görülmelidir.

Eğer işlem oblik yerine a.p. görüntüleme ile yapılacaksa, giriş noktası pedikülün lateral superior kadranıdır. Trokar, antero-medio-kaudal doğrultuda, transpediküler olarak vidalama hareketi veya çekiçle ilerletilir. Bu sırada, lateral görüntüde iğne pedikülün üst orta noktasında olmalıdır ve pedikülün orta noktasından, superior-inferior kenarı boyunca ilerletilir.

Vertebroplasti için iğne vertebra korpusunun 1/3 anterioruna kadar ilerletilirken, kifoplastide sadece posterior 1/3'e kadar ilerletilir.

Vertebroplastide, sement enjeksiyonu ile vertebra korpusunun tamamen doldurulmasına gerek yoktur. Önerilen, lomber bölgede $3-5 \mathrm{ml}$ sement enjeksiyonudur. Eğer sement orta hattan karşı tarafa yayılmadıysa, aynı işlem diğer taraftan tekrarlanır.

Kifoplastide, trokar vertebra korpusunun $1 / 3$ posterioruna ulaşınca, intraduser çıkartılır ve kanül yerinde bırakılır; kanülün içinden, elle kontrol edilen matkap ucu vertebra korpusunun anterioruna kadar ilerletilir. İdeal pozisyon, a.p. görüntüde matkabın ucunun orta hatta olmasıdır. Eş zamanlı olarak ikinci bir kanül, vertebranın karşı tarafından da aynı şekilde yerleştirilir. Bundan sonra, matkap uçları kanüllerden çıkartılır ve her kanülden söndürülmüş birer balon, matkap uçlarının oluşturduğu kavitelere yollanır. Balonlar, manometreye bağı kilitli şırıngalarla şişirilir. iki balon, birbiri ile öpüşen görüntüleri alınıncaya kadar şişirilir. Bu şişirmenin sınırları; maksimum basınç $<400$ psi veya istenen görüntüyü sağlayacak volüme erişmek, balon cidarının korteks kenarına ulaşması veya kifotik deformite düzelinceye kadardır. Bunu takiben balonlar söndürülür. Sement bu sırada karışım olarak hazırlanır ve 10-20 dk içinde sürekli floroskopi görüntüleme ile, oluşturulan kaviteye kanüllerin içinden ejekte edilir. Kifoplastide, hazırlanan kaviteler dolunca enjeksiyona son verilir.

Sement sızıntısı açısından, kifoplasti vertebroplastiye göre daha güvenli bulunmaktadır. Sement enjeksiyonu sonrası kanüller çıkartılır. Ekstravazasyonu önlemek için, yaklaşık $20 \mathrm{dk}$ kadar sementin donması beklenir; bu sırada hasta pron pozisyonda kalmalıdır. Bir defada üç seviyeden daha fazla enjeksiyon yapılması önerilmez.

Bu işlemler sırasında; epidural aralığa, disk aralığına veya vena kavaya olası bir sement sızıntısı olabilir. Bunun sonucunda; radiküler ağrı, mesane barsak disfonksiyonu, parapleji gibi nörolojik sekel gelişme riski vardır. Ayrıca; enfeksiyon, kanama, pulmoner emboli, lokal travma (örn; pedikül kırı̆ı̆, kök hasarı vb.), paralizi, hatta ölüm de, olası komplikasyonlardır.

\section{Spinal Kord Stimülasyonu (SKS)}

SKS, ağrı kontrolü için epidural aralığa elektrod yerleştirilerek, spinal korda elektrik enerjisi uygulaması esasına dayanan bir tedavidir. Bu teknikle; nöropatik ağrı, anjinal ağrı ve periferik iskemik ağrı tedavisi yapılmaktadır. SKS uygulamasının, 40 yıldan uzun zamandır kullanılmasına karşılık, analjezik etkisinin arkasındaki mekanizma hala tam olarak açıklığa kavuşmamıştır. Hasta seçimi, sistemin başarısı için temel unsurdur. Hastaya daha önce uygulanan konservatif tedavilerin başarısız olması, hastanın somatizasyon gibi psikiyatik probleminin olmaması ve deneme sürecinde ağrısının rahatlaması, işleme karar vermek için önemli kriterlerdir. 
Teknik: SKS implantasyon süreci iki aşamalıdır:

1) Eksternal stimülatör ile test süreci.

2) Kalıcı pil implantasyonu.

Test elektrodu, yerleştirilmesi sırasında lead skopi altında ağrılı dermatoma uyan posterior epidural alana yerleştirilir. Elektrod yerleştirilirken amaç, hastanın ağrısı olan bölge ile örtüşecek şekilde parestezi oluşturacak sinirleri depolarize etmektir. Etkin bir tedavi için, parestezinin bütün ağrılı bölgeyi kapsaması gerekir.

Ağrının bilateral, unilateral veya segmental oluşuna göre ve tek veya çift elektrod kullanımına göre, elektrodun yerine karar verilir. Örneğin; bilateral ağrılarda, eğer tek elektrod tercih edilmişse, katod alanının kordun fizyolojik orta noktasını hedeflemesi gerekir; unilateral ağrılarda $1 \mathrm{~mm}$ laterale doğru kayılması gerekebilir. Unilateral segmental ağrılarda ise elektrod daha lateralde, dorsal kök liflerini de stimüle edecek şekilde yerleştirilebilir. Ancak, bütün bu uygulamalar tam istendiği gibi yapılsa dahi kimi zaman, anatomik olarak tam istenen yerde parestezi alınması ağrıyı azaltmayabilir. Hastanın rahatlaması için ağrıı bölgede parestezi almanın gerekli, ancak çoğu zaman da yetersiz bir kriter olduğunun bilinmesi gerekir.

İşleme başlamadan önce, elektrodun yerleştirilmesi düşünülen seviyeye karar verilir. Lead'in epidural alana giriş noktası, hedef bölgenin daha kaudali olmalıdır. Epidural aralığa giriş açısının dar olması, lead'i yönlendirmeyi de kolaylaştırır. Bu nedenle, Tuohy iğnesi, hedeflenen seviyenin iki veya üç vertebra kaudalinden paravertebral olarak (pedikül üzerinden), iki seviye yukarıdaki interlaminer bölge hedeflenerek, sagittal plana yaklaşık $45^{\circ}$ oblik açı ile epidural alana yönlendirilir. Epidural aralığa girdikten sonra, lateral görüntü ile iğnenin içinden gönderilen elektrodun, posterior epidural bölgede ve a.p. görüntü ile orta hatta olduğu doğrulanır. Bundan sonra, lead istenen seviyeye kadar ilerletilir. Uygun bölgeye ulaşılınca, deneme stimülasyon ünitesi lead'in dışarıdaki ucuna bağlanır. Uyarı sırasında oluşan parestezinin ağrılı bölgeyi kapsaması amaçlanır. Bu sağlanınca, elektrod yerinde bırakılırken, iğne yavaşça ve elektrod yer değişmeyecek şekilde çıkartılır. Daha sonra elektrod fasyaya sabitlenir. Uzatma kablosu elektroda bağlanır. Bir kısım kablo bu bölgedeki cepte, halka şeklinde cilt altında bırakılırken, geri kalan proksimal kısım ciltten tünellenerek dışarı çıkartılır ve test sürecinde kullanılacak olan uyarı cihazına bağlanır.

Ortalama test süresi 5-7 gün arasında olup, bu süre içinde hastanın eğilme ve belden sağa sola dönme dışında (lead migrasyonuna neden olmamak için) aktivitelerini kısıtlaması istenir. Eğer deneme süreci başarılı geçerse, lead'e bağlanan yeni bir uzatma kablosu, yine cilt altından tünellenerek, kalıcı pil için oluşturulan cepte pile bağlanır.

SKS yerleştirilmesi ve sonrasında cerrahi işleme bağlı olarak birçok komplikasyon görülebilirse de, en sık karşılaşılan komplikasyonlar lead migrasyonu ve kırılmasıdır.

\section{SONUÇ}

Girişimsel ağrı tedavisinde amaç, çoğu kez altta yatan patolojinin tedavisinden çok, ağrı sinyallerinin iletilmesinin veya algılanmasının engellenmesidir. Buradaki algoritma; en az invaziv olandan, en fazla risk taşıyan, beceri, eğitim ve deneyim gerektiren yönteme doğru bir sıra izlenmesi şeklinde olmalıdır.

\section{KAYNAKLAR}

1. Travell JG, Simons DG. Myofascial Pain and Dysfunction: The Trigger Point Manual, Vol 2. Baltimore, Williams \& Wilkins, 1992.

2. Alvarez DJ, Rockwell PG. Trigger points: diagnosis and management. Am Fam Physician 2002;65(4):653-60.

3. Travell J, Simons D, Simons L. Myofascial Pain and Dysfunction, 2nd ed. Philadelphia: Lippincott Williams \& Williams; 1998.

4. Atkinson $\mathrm{MH}$. Osteoarthrosis. Can Fam Physician 1984;30:1503-7.

5. Paradise LA, Raj PP. Sacroiliac joint blocks. In: Lou L, Raj PP, Erdine S, Staats P, Waldman S, Racz G, Hammer M, Niv D, Ruiz-Lopez R, Heavner J, editors. Interventional Pain Management: Image-guided procedures, 2nd ed. Philadelphia, PA. Saunders Elsevier; 2008. p.429-42.

6. Panchal SJ. Sacroiliac Joint Injection and Radiofrequency Denervation. In: Deer TR, Leong MS, Buvanendran A, Kim PS, Panchal SJ, editors. Treatment of Chronic Pain by Interventional Approaches. New York: Springer-Verlag; 2015. p.331-39.

7. Izzo R, Popolizio T, D’Aprile P, Muto M. Spinal pain. Eur J Radiol 2015;84(5);746-56. Crossref

8. Bogduk N, Wilson AS, Tynan W. The human lumbar dorsal rami. J Anat 1982;134(Pt 2):383-97.

9. Dreyfuss $P$, Rogers $C$. Radiofrequency neurotomy of the zygapophyseal and sacroiliac joints. In: Lennard T, editor: Pain Procedures in Clinical Practice, 2nd ed. Philadelphia: Hanley \& Belfus; 2000.

10. Bogduk N. International Spinal Injection Society Practice Guidelines and Protocols. Lumbar medial branch blocks. ISIS Newsletter, 2002.

11. Dreyfuss P, Halbrook B, Pauza K, Joshi A, McLarty J, Bogduk $\mathrm{N}$. Efficacy and validity of radiofrequency neurotomy for chronic lumbar zygapophysial joint pain. Spine (Phila Pa 1976) 2000;25(10):1270-7.

12. van Kleef M, Barendse G, Kellels A, Voets HM, Weber WE, de Lange $S$. Randomized trial of radiofrequency lumbar facet denervation for chronic low back pain. Spine (Phila Pa 1976) 1999;24(18):1937-42.

13. Nagda JV, Davis CV, Bajwa ZH, Simopoulos TT. Retrospective review of the efficacy and safety of repeated pulsed and continuous radiofrequency lesioning of the dorsal root ganglion/segmental nerve for lumbar radicular pain. Pain Physician 2011;14(4):371-6. 
14. Rosenthal R. Radiofrequency Lesioning. In: Waldman SD, editor. Pain Management, 2nd ed. Philadelphia: Elsevier/ Saunders; 2011. p.1331-60.

15. Grigsby E, Deer T, Weiner R, Wilcosky B, Kramer J. Prospective, Multicenter, Clinical Trial Studying Dorsal Root Ganglion Stimulation in the Treatment of Back Pain. North American Neuromodulation Society, 2010.

16. Teixeira A, Grandinson M, Sluijter ME. Pulsed radiofrequency for radicular pain due to herniated intervertebral disc -an initial report. Pain Pract 2005;5(2):111-5.

17. Melnik I, Derby R, Baker RM. Provocative Discography. In: Deer TR, Leong MS, Buvanendran A, Kim PS, Panchal SJ, editors. Treatment of Chronic Pain by Interventional Approaches. New York: Springer-Verlag; 2015. p.253-68.

18. Greenspan A, Amparo EG, Gorczyca DP, Montesano PX. Is there a role for diskography in the era of magnetic resonance imaging? Prospective correlation and quantitative analysis of computed tomography-discography, magnetic resonance imaging, and surgical findings. J Spinal Disord 1992;5(1):26-31.

19. Landers $\mathrm{MH}$, Jones RL, Rosenthal RM, Derby R. Lumbar Spinal Neuroaxial Procedures. In: Lou L, Raj PP, Erdine S, Staats P, Waldman S, Racz G, Hammer M, Niv D, RuizLopez R, Heavner J, editors. Interventional Pain Management: Image-guided procedures, 2nd ed. Philadelphia, PA. Saunders Elsevier; 2008. p.322-67.

20. Walsh TR, Weinstein JN, Spratt KF, Lehmann TR, Aprill C, Sayre H. Lumbar discography in normal subjects: A controlled, prospective study. J Bone Joint Surg Am 1990;72(7):1081-8.

21. Heary RF. Intradiscal electrothermal annuloplasty: the IDET procedure. J Spinal Disord 2001;14(4):353-60.

22. Saal JA, Saal JS. Intradiscal electrothermal treatment for chronic discogenic low back pain: Prospective outcome study with a minimum 2-year follow-up. Spine (Phila Pa 1976) 2002;27(9):966-73.
23. Deen HG, Fenton DS, Lamer TJ. Minimally invasive procedures for disorders of the lumbar spine. Mayo Clin Proc 2003;78(10):1249-56.

24. Kapural L. Intradiscal Annuloplasty for the Treatment of Discogenic Pain. In: Deer TR, Leong MS, Buvanendran A, Kim PS, Panchal SJ, editors. Treatment of Chronic Pain by Interventional Approaches. New York: Springer-Verlag; 2015. p.297-306.

25. Ruiz-Lopez R, Pichot C. Percutaneous Therapeutic Procedures for Disc Lesions. In:. Lou L, Raj PP, Erdine S, Staats P, Waldman S, Racz G, Hammer M, Niv D, Ruiz-Lopez R, Heavner J, editors. Interventional Pain Management: Imageguided procedures, 2nd ed. Philadelphia, PA. Saunders Elsevier; 2008. p.539-58.

26. Sluijter ME. Radiofrequency lesions of the communicating ramus in the treatment of low back pain. In: Raj PP, editor. Current management of pain. Philadelphia: Kluwer Academic publishers; 1989. p.145-59.

27. Racz GB, Noe CE. Pelvic Spinal Neuroaxial Procedures. In: Lou L, Raj PP, Erdine S, Staats P, Waldman S, Racz G, Hammer M, Niv D, Ruiz-Lopez R, Heavner J, editors. Interventional Pain Management: Image-guided procedures, 2nd ed. Philadelphia, PA. Saunders Elsevier; 2008. p.405-28.

28. Kallewaard JW, Vanelderen P, Richardson J, Van Zundert J, Heavner J, Groen GJ. Epiduroscopy for patients with lumbosacral radicular pain. Pain Pract 2014;14(4):365-77. Crossref

29. Verlan JJ, Oner FC, Verbout AL, Dhert WJ. Temperature elevation after vertebroplasty with polymethyl-methacrylate in the goat spine. J Biomed Mater Res B Appl Biomater 2003;67(1):581-5.

30. Kim PS. Vertebral Augmentation:Vertebroplasty and Kyphoplasty. In: Deer TR, Leong MS, Buvanendran A, Kim PS, Panchal SJ, editors. Treatment of Chronic Pain by Interventional Approaches. New York: Springer-Verlag; 2015. p. $341-50$ 